\title{
DIFICULDADES APONTADAS PELO AGENTE COMUNITÁRIO DE SAÚDE NA REALIZAÇÃO DO SEU TRABALHO
}

\author{
DIFFICULTIES POINTED OUT BY COMMUNITY \\ HEALTH WORKERS IN HOME VISIT
}

\begin{abstract}
Vagner Ferreira do Nascimento', Ana Cláudia Pereira Terças ${ }^{2}$, Thalise Yuri Hattori³, Bianca Carvalho da Graça ${ }^{4}$, Juliana Fernandes Cabral', Josué Souza Gleriano6, Angélica Pereira Borges ${ }^{7}$, Graziela Regina Machado de Souza Ribeiro8
\end{abstract}

\begin{abstract}
RESUMO
Este estudo objetivou conhecer as dificuldades apontadas pelo agente comunitário de saúde na realização do seu trabalho. Foi realizado em novembro de 2015 no município de Tangará da Serra Mato Grosso, com agentes comunitários de saúde atuantes em 22 estratégias de saúde da família. Utilizou-se questionário semiestruturado e para análise dos dados, aplicou-se parte da análise lexical com análise de conteúdo. Foram relatadas dificuldades subsistentes, como 0 acesso às residências dos moradores, recusa da visita pelo morador, ausência de reconhecimento profissional, fragilidade no trabalho em equipe e falta de materiais. Como estratégias para a minimização/solução desses entraves estão a articulação entre a equipe multiprofissional, sensibilização da comunidade e dos gestores, alocação de recursos e capacitação contínua, possibilitando maior controle social e práticas laborais mais satisfatórias e qualificadas.
\end{abstract}

Descritores: Agentes Comunitários de Saúde; Saúde da Família; Capacitação em Serviço.

\begin{abstract}
This study aimed to identify the difficulties pointed out by community health workers in home visit. It was held in November 2015 in the city of Tangara da Serra - Mato Grosso, with community health workers active in 22 family health strategies. We used semi-structured questionnaire and data analysis, applied part of the lexical analysis with content analysis. Remaining difficulties have been reported, such as access to the homes of residents, refusal of the visit by the resident, lack of professional recognition, weakness in teamwork and lack of materials. As strategies for minimizing I solution of these obstacles are the link between the multidisciplinary team, community outreach and managers, resource allocation and continuous training, allowing greater social control and more satisfactory and qualified labor practices.
\end{abstract}

Descriptors: Community Health Workers; Family Health; Inservice Training.
${ }^{1}$ Doutorando em Bioética pelo Centro Universitário São Camilo (CUSC), São Paulo, SP, Brasil.

${ }^{2}$ Doutora em Medicina Tropical pela Fundação Oswaldo Cruz (FIOCRUZ), Rio de Janeiro, RJ, Brasil.

${ }^{3}$ Mestre em Ciências da Saúde pela Universidade Federal da Grande Dourados (UFGD), Dourados, MS, Brasil.

${ }^{4}$ Graduanda de Enfermagem na Universidade do Estado de Mato Grosso (UNEMAT), Tangará da Serra, MT, Brasil.

${ }^{5}$ Mestre em Saúde Coletiva pela Universidade Federal de Mato Grosso (UFMT), Cuiabá, MT, Brasil.

${ }^{6}$ Mestre em Saúde Coletiva pela Universidade Católica de Santos (UniSantos), Santos, SP, Brasil.

\footnotetext{
${ }^{7}$ Mestre em Enfermagem pela Universidade Federal de Mato Grosso (UFMT), Cuiabá, MT, Brasil.

${ }^{8}$ Enfermeira especialista em Saúde da Família pela Escola de Saúde Pública (ESP), Cuiabá, MT, Brasil.
} 


\section{Introdução}

O trabalho do Agente Comunitário de Saúde (ACS) tem importância fundamental na Atenção Primária à Saúde (APS) para a concretização da Estratégia Saúde da Família (ESF). O ACS é o agente nuclear das ações de saúde na comunidade ao realizar as atividades de vigilância, prevenção das doenças e promoção à saúde, por meio das visitas domiciliares e educação em saúde, tanto de forma individual quanto coletiva, desenvolvidas em conformidade com as diretrizes do Sistema Único de Saúde (SUS) e sob supervisão do gestor local. Além disso, o ACS é considerado o elo entre a equipe de saúde da família e a comunidade assistida; relação que está baseada no vínculo e na confiança, facilitando o diagnóstico das situações de risco ${ }^{1-4}$.

E através da visita domiciliária, entendida como o principal instrumento de trabalho dos ACS's, estes profissionais estabelece e fortalece as relações com as famílias, facilitando a identificação de problemas intrínsecos àquele contexto comunitário, que muitas vezes outros profissionais da equipe desconhecem. Por meios das visitas, verificam quais indivíduos estão expostos a maiores riscos de adoecer ou morrer e que precisam de mais atenção e cuidados ${ }^{2,5}$.

Nessa perspectiva, o ACS pode colaborar para o empoderamento dos indivíduos e da comunidade, porém, é necessário refletir em que condições vem se consolidando a prática deste profissional no SUS. Alguns aspectos são limitantes ao seu trabalho, como as questões socioeconômicas das famílias, dificuldades no acolhimento e vínculo com algumas famílias, baixa remuneração, falta de capacitação, falta de resolutividade dos casos, de reconhecimento profissional por parte da população, de instrumentos e tecnologias. Além das limitações dificultarem a operacionalização de um trabalho voltado à integralidade do cuidado, refletem negativamente na saúde dos próprios ACS's, seja de forma física ou psicoemocional ${ }^{3,4,6,7}$.

Outras dificuldades, principalmente nas visitas domiciliares têm sido relacionadas ao trabalho do ACS, associadas às questões logísticas e ambientais. Destacando-se, empecilhos para encontrar as pessoas em casa, o mau tempo, distância entre os domicílios, animais soltos, precarização de estradas, domicílios fechados e, em algumas localidades ainda, o convívio com o tráfico de drogas e os riscos das doenças infectocontagiosas ${ }^{3,8}$.

Ainda, estão expostos a violência de todas as classificações, requerendo uma capacidade de recriar a maneira de trabalhar, muitas vezes solitária ou no máximo, em pares. A experiência de presenciar situações de violência no seu cotidiano faz muitos amadurecem nas relações estabelecidas com a comunidade, de modo a recusarem determinado tipo de visita e/ou solicitar apoio extra para esse acompanhamento familiar ${ }^{3,5}$.

Esses profissionais apontam alguns fatores para desmotivação do trabalho, como, a falta do reconhecimento pelo poder público, desvalorização financeira e ausência de progressão na carreira. Muitos não possuem vínculo institucional efetivo, produzindo limitações no trabalho com a comunidade e ESF, podendo ainda, gerar insegurança profissional e fragilidade para a concretização dos princípios da APS. Portanto, há a necessidade da criação de dispositivos de fortalecimento da dimensão política e se tem indicado que a participação do ACS em instâncias decisórias pode oportunizar o fomento das discussões trazidas pelo reflexo do trabalho e maior visibilidade no contexto prático de suas ações ${ }^{5,6}$.

Dessa forma, torna-se fundamental revelar as problemáticas que prejudicam o pleno desempenho das atividades diárias desse profissional, para intervir de forma efetiva nos cenários assistenciais. A partir disso, esse estudo objetivou conhecer as dificuldades apontadas pelo agente comunitário de saúde na realização do seu trabalho.

\section{Metodologia}

Tratou-se de um estudo descritivo, exploratório, com abordagem qualitativa, realizado junto aos ACS's, pertencentes a 22 ESF's localizadas no maior município da região do Médio Norte de Mato Grosso. A importância de estudar grupos profissionais dessa localidade é mediante os desafios enfrentados frente a diversidade étnica da comunidade atendida (indígenas, quilombolas e migrantes de vários estados brasileiros), a variedade de agravos notificáveis de importância nacional (Hanseníase, Leishmaniose e Hantavirose). Essa localidade ainda apresenta baixa cobertura de ESF, deduzindo uma população com acompanhamento familiar superficial, fragmentado ou ineficaz.

A pesquisa foi realizada no mês de novembro de 2015, no auditório do Centro de Formação e Atualização dos Profissionais da Educação Básica de Mato Grosso (CEFAPRO/MT), com o preenchimento de um questionário aplicado ao término do Curso de Aperfeiçoamento em Saúde da Família: uma abordagem ao processo de trabalho do ACS, 
promovido pelo Núcleo de Pesquisa e Extensão em Política, Planejamento, Organização e Práticas (individual e coletiva) em Saúde (NPEPS) da Universidade do Estado de Mato Grosso (UNEMAT) em parceria com a Prefeitura Municipal dessa localidade.

Os sujeitos participantes da pesquisa foram: ACS com idade superior a 18 anos; que participaram do curso de aperfeiçoamento; que atuassem no mínimo há seis meses na função de ACS nesse município. Foram excluídos os sujeitos que verbalizaram cansaço físico/mental.

Para definição da amostra, utilizou-se amostragem não probabilística, por conveniência, perfazendo um universo de 71 ACS's. E por não ter ocorrido perdas, após aplicação dos critérios definidos, o tamanho amostral correspondeu ao mesmo quantitativo. Porém, para definição do quantitativo de discursos a ser utilizado, empregou-se a saturação dos dados.

A coleta de dados ocorreu no último momento do curso de aperfeiçoamento, depois do encerramento de todas atividades teórico-práticas. Após entrega do questionário semiestruturado, composto por questões fechadas (dados sociodemográficos) e questão aberta (dificuldades no trabalho do ACS), foi disponibilizado 45 minutos para 0 preenchimento e posterior recolhimento.

Para análise do material empírico, organizou os dados em quadros consecutivos, identificando e agrupando similaridades que permitisse a aplicação parcial da análise lexical com a análise de conteúdo ${ }^{9}$. A primeira etapa da análise lexical consistiu em averiguar ou medir a dimensão das respostas, com a chamada aproximação lexical, chegando-se às palavras de conteúdo ou significado. A partir disso, fez-se a chamada navegação lexical, que consiste em ir diretamente às respostas onde foi citada a palavra em questão, além de possibilitar apresentação de estatística lexical, principalmente pela Frequência de Aparição (FA) das palavras. Para esta análise, foi preparado um corpus buscando-se a correção dos erros ortográficos e vícios de linguagem correspondente à língua portuguesa (Brasil) ${ }^{10}$.

O corpus originou seis classes lexicais, nomeadas de acordo com a análise dos significados e sentidos das palavras correspondentes. No entanto, foram explorados e discutidos os conteúdos presentes em quatro classes, onde concentraramse os léxicos mais adequados aos objetivos deste estudo. De acordo com os sentidos léxicos, foram categorizadas e nomeadas em: "Logística das visitas domiciliares", "Práticas assistenciais do ACS", "Relações interpessoais com a equipe", "Disponibilidade de materiais". No recorte das narrativas utilizadas houve decodificação do tipo alfanumérica, onde a consoante $\mathrm{P}$ significa participante e o número arábico que compõe o conjunto representa a ordem de apresentação.

Foram respeitados todos os aspectos éticos em pesquisa, de acordo com a Resolução 466/12, iniciando somente após apreciação e aprovação do Comitê de Ética em Pesquisa com Seres Humanos (CEP) da UNEMAT, a partir do CAAE: 149412215.2 .0000 .5166 e parecer favorável n. 1.280.421. Assim, a participação dos sujeitos ocorreu de forma voluntária, garantindo a preservação e sigilo de suas identidades, com total autonomia para se recusar e/ou se retirar da pesquisa em qualquer momento, todos assinaram o Termo de Consentimento Livre e Esclarecido (TCLE) em que concordavam em participar da pesquisa.

\section{Resultados e Discussão}

O perfil dos ACS que atuam em Tangará da Serra corrobora com achados da literatura. Sendo a maioria do sexo feminino ${ }^{11,12}$ com idade variando entre 18 e 59 anos e predomínio de pessoas jovens na faixa etária de 20 a 29 anos, casados, com filhos, raçalcor parda e ensino médio completo ${ }^{11-13}$. Destaca-se também, a participação desses profissionais, cursando ensino superior e tecnológico.

Cabe destacar ainda, que a renda familiar média é de até dois salários mínimos, sendo que a maioria reside em casa própria e não possui outra atividade profissional com renda. 0 tempo de trabalho predominante entre esses profissionais é de um a dois anos.

As dificuldades mencionadas no cotidiano do trabalho dos ACS's foram ilustradas por meio das seguintes palavras: pacientes (FA 25), casas (FA 17), equipe (FA 12) e falta (FA 12), remetendo às problemáticas do trabalho em equipe e dos aspectos socioambientais na execução das visitas domiciliares. 
Quadro 1- Quantitativo de palavras por respostas dos ACS's ( $n=71)$ - Dificuldades apontadas por agentes comunitários de saúde para realização do seu trabalho, em resposta ao questionamento: Qual sua maior dificuldade no trabalho como ACS?

\begin{tabular}{|c|c|c|}
\hline Elementos textuais (palavras) & Número de citação & Frequência (\%) \\
\hline Sem resposta & 35 & 49,3 \\
\hline Menos de 35 & 32 & 45,1 \\
\hline De 35 a 45 & 3 & 4,2 \\
\hline De 46 a 60 & 1 & 1,4 \\
\hline TOTAL & 71 & 100 \\
\hline \multicolumn{2}{|c|}{ Mínimo = 01, Máximo = 60, Soma= 530, Média= 11,9 } \\
\hline
\end{tabular}

Fonte: Pesquisa Direta.

\section{Logística das visitas domiciliares}

A visita domiciliária é a competência que melhor representa a atuação do ACS, sendo permeada por objetivos, como o contato ativo com as famílias englobadas na microárea de sua responsabilidade, bem como seu cadastramento na ESF e acompanhamento por médicos, enfermeiros, odontólogos e demais profissionais da saúde, a fim de permitirem ao ACS desenvolver estratégias que visem a prevenção de doenças e promoção da saúde ${ }^{14}$. No entanto, algumas barreiras, sobretudo as ambientais, perfazem as visitas domiciliares, dificultando a sua prática. Dentre elas, destacam-se o acesso dificultado às residências, condições climáticas desfavoráveis, ambientes de visitação nem sempre agradáveis e seguros, representando riscos potenciais aos profissionais que exercem seu trabalho nas respectivas circunstâncias, como observado nas narrativas $3,8,15$.

Distância e em períodos chuvosos muita lama. Já perdi papéis importantes por conta dessas condições [...], mas nunca melhoram nosso trabalho. (P1)

[...] Nem todas agentes possuem moto [...]. Quando desço para minha área, voltar naquele sol é pedir para morrer. $(P 2)$

Chegar em lugares de difícil acesso, dentro de mata fechada, passar por meio de gado e enfrentar cães. (P3)

Dificuldade de acesso entre as casas e o serviço. É difícil planejar as atividades para atender todas as minhas casas, perdemos muito tempo entre as visitas [...]. (P4)

Só com moto para conseguir em alguns lugares, muito longe da unidade e perigoso. [...] poderiam informatizar os dados dos pacientes, aí conseguiria registrar quase que instantâneo pelo meu celular. (P5)

Pelo fato do ACS ser responsável por um território de até 750 pessoas, e por vezes possuir grande extensão, há necessidade de percorrer longas distâncias, nas quais a disponibilidade de carro não ocorre de modo integral, sendo complementar ou único o deslocamento por meio de bicicletas e outros meios de locomoção. Assim, a caminhada se apresenta como uma das principais e mais acessíveis alternativas para esses profissionais ${ }^{7,15}$.

Na compreensão desse tipo de recurso como oportuno para a realização da visita domiciliar, o ACS se esbarra além do obstáculo à distância das residências, aos riscos de agressões com animais que se encontram no percurso ou nos quintais visitados ${ }^{3,15}$. Existe também, o risco de picadas de insetos transmissores de doenças como a dengue, febre amarela e malária, comumente encontrados em locais de terrenos baldios, com água parada, lixos e quintais sujos ${ }^{4}$. Para os ACS's de área rural há ocorrências com acidentes por animais peçonhentos, como serpentes, aranhas e escorpiões ${ }^{3,4,15}$. 
Outra dificuldade enfrentada pelo ACS nas visitas domiciliares é a exposição aos fatores climáticos, ora ao sol desgastante, ora às mudanças repentinas do tempo. Os relatos desses profissionais evidenciam que suas condições de trabalho esporadicamente são insalubres, onde passam horas sob à luz solar, estando conforme estudos susceptíveis a adquirir manchas e/ou queimaduras, que seriam evitadas se recebessem materiais simples de seus gestores, como protetor solar, óculos protetores de raios UVA e UVB e capa de chuva, já que situações como essas são vivenciadas diariamente devido as áreas demasiadamente distantes da unidade de saúde ${ }^{15}$.

As dificuldades de acesso, das condições climáticas, ocorrência de transmissão de doenças infectocontagiosas, barreiras físicas, organizacional e de recursos materiais também foram relatados em outros estudos ${ }^{1,3,4,12,16}$, razões que, inviabilizam o acompanhamento de todas as famílias sob sua responsabilidade. As dificuldades e desafios estão proporcionalmente relacionados à vulnerabilidade social da microárea atendida ${ }^{3}$.

Observa-se dessa forma, que a visita domiciliar consiste em uma das ações base do ACS quanto a organização assistencial na APS, que envolve a aproximação do usuário ao serviço de saúde, bem como o conhecimento das suas necessidades. Contudo, nesse contexto, existem diversos fatores que dificultam a eficácia desse trabalho e que por vezes, envolvem riscos à saúde e integridade desses profissionais. Assim, cabe um olhar diferenciado de ações por parte dos gestores e do próprio serviço em otimizar e minimizar esses riscos de maneira a melhorar as condições relatadas.

\section{Práticas assistenciais do ACS}

O trabalho do profissional de saúde, em especial do ACS, ocupa posição estratégica no desenvolvimento das políticas públicas brasileiras em decorrência do aumento de sua atuação nas práticas de saúde, nos aspectos quantitativo e qualitativo. O ACS integra uma equipe multidisciplinar, exercendo atividades que influenciam o processo saúde-doença da comunidade ${ }^{14}$.

Seu trabalho se baseia nas dimensões técnica, política e social. Enquanto componente técnico, remete ao atendimento das famílias visando a prevenção de doenças e monitoramento dos agravos já estabelecido na população adstrita. O campo político faz referência à atuação do ACS como orientador do modelo de atenção à saúde, fomentador do autocuidado, cidadania e das transformações sociais. Na parte social, remete quanto a resolução das questões sendo uma delas a de acesso ao serviço $0^{3,17}$.

No processo de formação dos ACS's, preconiza-se além da compreensão dos saberes básicos dos determinantes da saúde, ações educativas para a troca de conhecimentos, experiências e promoção da participação coletiva no enfrentamento de desafios presente no processo saúde doença ${ }^{13}$. Mas, alguns profissionais se esbarram, frequentemente, em questões que perpassam os saberes técnicos, como, a pouca receptividade das famílias.

Enfrentamos muitas barreiras, principalmente para ser recebida nas casas. Não tive curso para aprender fazer visitas domiciliares, aprendi com meus colegas, e eles também têm essas dificuldades [...]. As famílias demoram para nos aceitar, ficam receosas com a nossa entrada na casa. (P6)

É frequente alguns pacientes não abrirem a porta de suas casas ou recusar a visita. Algumas vezes não sei como agir, ter que cuidar e ser impedido disso [...] (P7)

Na prática da visita domiciliar, ao chegarem nas residências, os ACS's enfrentam a problemática de não serem recebidos pelas famílias, dificuldades de encontrar o usuário em sua residência, portões fechados, sobretudo moradores que relatam não quererem ser incomodados pelos ACS's. Segundo as famílias, essa rejeição ocorre normalmente porque no momento da visita domiciliária não necessitam de seus cuidados, o que revela o desconhecimento das atribuições desse profissional e da ESF, levando a desvalorização desse trabalho, em decorrência das compreensões equivocadas ${ }^{4,6,11,17}$.

Existe também, os casos de resistência dos moradores de maior poder aquisitivo, que optam pelos planos de saúde privados ao invés do serviço oferecido pelo SUS. Além das situações associadas com violência relacionado à roubos e casos de recusa na adoção de mudanças de hábitos no que diz respeito ao cuidado com a prevenção de doenças e a promoção da saúde 5 . 
Percebe-se a necessidade de mudanças, visto que as propostas da ESF que são baseadas na prevenção e promoção da pessoa em sua integralidade não estão sendo efetivas ${ }^{2,7}$. Um exemplo disso é observado de como um bom acolhimento da família ao ACS contribui beneficamente o relacionamento com a equipe da ESF2,3,16. Ainda que haja, a construção de vínculos com a comunidade assistida pelo ACS para se efetivar a longitudinalidade na APS, esse profissional apresenta suas próprias deficiências.

\section{Tenho dificuldades, algumas vezes para abordar os pacientes em suas casas. [...] me falta palavras e aquele jeito correto de falar. (P8) \\ Ás vezes sofro em como falar em público. Preciso superar isso urgente [...]. Fiz uma vez um curso de oratória, mas é diferente dentro de uma sala de aula [...], há alguém para te corrigir e te guiar. (P9)}

Os ACS's necessitam aprimorar suas habilidades comunicacionais quanto à abordagem dos moradores de sua área de abrangência de acordo com as demandas do usuário, por um processo onde se integrem a percepção, assimilação e transmissão de informações claras, objetivas e suficientes. Este processo abrange a dimensão verbal e não verbal, onde o profissional deve se precaver em relação ao tom de voz, discurso precursor, gestos complementares à fala, postura e distância que mantém do ouvinte, considerando o mesmo em sua integralidade/singularidade e o fato de estar adentrando a privacidade de sua família e residência ${ }^{18}$.

Assim, ações comunicativas quando bem trabalhadas, consegue assegurar a integração social que traz dignidade e gratidão ao trabalho de mediação. Quando realizadas nas visitas domiciliares, ela se apresenta de forma genuína e sem coerções que são repassadas cooperativamente de forma a ser compreendida e seguida ${ }^{12}$.

Receios e dificuldades em solucionar os problemas com a comunidade costumam ser comuns ${ }^{5,10,16}$, sendo necessário uma capacitação do ensino aprendizagem aplicável aos aspectos de vida da sua comunidade. A capacitação realizada com os ACS's contribuíram para as atividades de encaminhamento para atendimento clínico e educação em saúde no estudo de Costa et al ${ }^{1}$, dessa forma, observa-se um melhor preparo para as inúmeras atribuições desse profissional que traz como consequência o reconhecimento da sua atuação com a comunidade. Essa aproximação fará com que o ACS consiga a enfrentar esses desafios e aprenda a lidar com as pessoas ${ }^{3}$. Habilidades como essas são fatores que proporcionam maior segurança e confiança na relação assistencial, pois facilitam o enfrentamento de situações cotidianas difíceis ${ }^{18}$.

OACS deve ter entre as suas habilidades, saber exercer múltiplos papéis como o de educador, ouvinte, conselheiro e monitor para que se consiga atender a particularidade do indivíduo, da família ou da comunidade ${ }^{17}$. No entanto, as dimensões do cuidado exigem também, experiência e feeling, o que solicita do profissional habilidades específicas, porém nem sempre encontradas.

Minha dificuldade é no acompanhamento de pacientes especiais e acamados. Muitas vezes, precisam de muitos recursos em saúde, presença do enfermeiro e do médico em todas as visitas [...]. (P10)

[...]Acho que é um consenso entre nós, a dificuldade no cuidado com os idosos, devido à dificuldade que eles têm ao administrarem medicações e seguir o tratamento médico. (P11)

Tocar em assuntos que envolvam a higiene da pessoa [...], a diversidade cultural em saúde é muito difícil. (P12)

Acho que minha dificuldade é assistir pacientes da área de saúde mental. (P13)

O lidar com os diferentes públicos implica em saber desenvolver a capacidade de observação e comunicação, principalmente para as atividades relacionadas as atribuições do ACS. Atribuições que envolve identificar as áreas de risco, realizar o acompanhamento das famílias adstritas ao seu território além da realização das ações coletivas e intersetoriais ${ }^{17}$.

Freitas et al. ${ }^{10}$ também encontraram limitações quanto a conhecimentos da saúde mental, vigilância em saúde, procedimentos técnicos de saúde. Para isso, é necessário que o ACS capacidade técnica para que se consiga atender as demandas mais comuns como orientações quanto a administração de medicamentos, higiene até as mais complexas 
que exigem maior cuidado bem como de algumas áreas específicas como é o caso da saúde mental para que assim, consiga se atingir a integralidade do cuidado nos aspectos da cultura, linguagem e costumes e do acompanhamento de diferentes públicos e situações ${ }^{3,19}$.

Uma vez que nem sempre é possivel realizar o acompanhamento de todas as famílias conforme observado nesse e em outros estudos ${ }^{1,3,12}$. Há necessidade dos profissionais priorizarem as famílias de risco, como os idosos e acamados, indivíduos com transtornos mentais, onde o profissional deve se atentar para o estado de saúde do indivíduo, verificando adesão ao plano terapêutico, avaliação de riscos ambientais, lesões cutâneas, integridade de pés, presença de úlceras por pressão (UPP) e outros agravos importantes, e se necessário, encaminhá-lo à ESF para cuidados mais específicos ${ }^{20,21}$.

\section{Relações interpessoais e descontentamentos com a equipe}

Assim como nos demais setores de saúde, a atuação na ESF requer desenvolvimento de habilidades sociais suficientes para o trabalho em equipe, fazendo-se ainda mais importante ao reconhecer que o êxito dessa assistência se completa na multi e interdisciplinaridade desse coletivo de profissionais. Mas, o processo que define as relações interpessoais no trabalho se constrói diariamente, a partir dos comportamentos assumidos pelos profissionais na compreensão de histórias, crenças, emoções, expectativas e problemas pessoais dos outros. A desarmonia das relações interpessoais dentro da dinâmica de trabalho, parece influenciar o comportamento dos profissionais, como exposto nas narrativas.

O reconhecimento e respeito de alguns profissionais da unidade de saúde da familia (USF). (P14)

Realização de visita domiciliar com equipe de enfermagem e médica. (P15)

A participação da parte médica e enfermagem conosco é falha, pois alguns assuntos não são finalizados e alguns problemas não são solucionados. (P16)

A equipe toda abraçar a causa, aceitar as situações e problemas da comunidade [...]. (P17)

É muito conflito entre a equipe, pessoas orgulhosas, equipe desunida. (P18)

O trabalho da equipe multidisciplinar de saúde demanda trocas de teorias e métodos de modo que os saberes dos pares sejam integrados para a potencialização dos processos interativos e soluções de problemas emergentes, bem como sua prevenção ${ }^{6}$. Há duas modalidades dessa metodologia profissional: a equipe agrupamento e equipe integração, onde há uma união dos trabalhadores e ações, enfatizando as singularidades das atuações e interação profissional com práticas articuladas, evidenciada pela divisão das atribuições, respectivamente ${ }^{12}$.

OsACS's são os primeiros profissionais a identificarem problemas com o usuário e em decorrência disso, pode haver a necessidade do cuidado de outros profissionais, como os técnicos de enfermagem e enfermeiros. Esses profissionais são mais solicitados devido à proximidade com as famílias, precisão e o poder de resolutividade na direção da satisfação do usuário ${ }^{1,4,6,10,11}$. Por vezes, essa proximidade é vista e avaliada pelo ACS com cautela como prejudicial, uma vez que a população não consegue separar o lado pessoal com o profissional, a privacidade pessoal fica comprometida ${ }^{4,5,8}$.

Contudo, em relação às visitas domiciliares, os ACS's consideram esse envolvimento multiprofissional carente, enfatizando a questão da prioridade dos atendimentos internos das unidades de saúde em detrimento das visitas e atividades extra muro ${ }^{12}$. Devido à essa ausência multiprofissional, a população por vezes, acaba exigindo cuidados que não competem ao ACS, como procedimentos médicos e de enfermagem ${ }^{1,5,16,17}$.

Depoimentos de profissionais da saúde e pacientes revelam que a equipe necessita realizar uma assistência de forma mais sistematizada, porém aspectos como a valorização diferenciada entre as categorias, indefinições dos papéis e relações interpessoais desgastantes, corroboram para a fragmentação do cuidado ${ }^{16,21,22}$. Outros estudos também encontraram conflitos laborais relacionados a questão relacionamento interpessoal, organização do trabalho e de hierarquia no serviço, $0^{4,2,21,23}$. Entretanto, observa-se como o bom relacionamento da equipe facilitou de forma positiva o trabalho do ACS ${ }^{3,11}$.

Dessa forma, problemas de comunicação e organização da equipe, prejudicam os momentos de trocas, planejamento, discussão, avaliação e planejamento da assistência. Assim, sugerem-se como estratégias resolutivas, a modificação dos atendimentos de caráter individualizado, melhoria no processo de comunicação com o uso da linguagem 
fácil e acessível, valorização dos conhecimentos ímpares, envolvimento de todos os profissionais nas reuniões e nas decisões participativas, bem como corresponsabilização e reflexão sobre suas competências ${ }^{3,12,23}$.

\section{Disponibilidade de materiais}

Os problemas que envolvem os recursos materiais nos serviços públicos de saúde e sua adesão no dia a dia da prática assistencial consistem em: dificuldade de acesso, estrutura organizacional inapropriada, aquisição imprudente, carência de recursos financeiros, precipitação dos profissionais, resistência, monotonia no atendimento, inabilidade e desconhecimento da proteção oferecida. Observa-se que tais fatores se relacionam tanto a falhas advindas da instituição como dos próprios profissionais, quanto a disponibilidade e 0 uso de equipamentos e materiais de trabalho ${ }^{24}$, como expressado pelos ACS's do estudo.

\section{[...]. (P19).}

A falta de EPl's é um dos nossos maiores problemas para efetuar nosso trabalho

Há muita falta de materiais essenciais para o dia a dia. Para nos proteger de doenças, às vezes algum bicho do mato. (P20).

Sair ao sol quente, sem protetor solar em longa distância [...]. (P21).

Se você não tiver guarda sol, chapéu, óculos escuros, ninguém se preocupa com você [...]. (P22)

O uso de equipamentos de proteção individual (EPI's) pelos trabalhadores objetiva a proteção coletiva, sendo recomendado, primordialmente, quando suas profissões oferecem riscos à exposição de agentes patogênicos e materiais biológicos. Esses instrumentos são preconizados no atendimento a todos os pacientes, sem levar em consideração seu diagnóstico clínico, visando sobretudo, a segurança dos envolvidos na assistência ${ }^{24}$.

Por exemplo, nas atividades desenvolvidas em comunidades rurais é importante destacar que o ACS supre, muitas vezes, a falta de outros profissionais. E isso, impõe ao seu trabalho, maiores riscos ergonômicos e ambientais ${ }^{15,25}$, exigindo EPl's específicos, geralmente adquiridos com recursos do profissional.

Independentemente da localização geográfica, todos os ACS's estão expostos à insolação durante a realização das visitas domiciliares. Grande maioria reconhecem a gravidade dessa incidência diária e continua, mas assentem a circunstância por não perceberem manifestação positiva de suas chefias e gestores ${ }^{8}$. Vários são os estudos ${ }^{4,8,16,17}$ que apontaram as condições insalubres e os riscos ocupacionais aos quais estão sujeitos diariamente.

Assim, a biossegurança é fundamental para prevenir, minimizar e eliminar riscos que possam interferir negativamente na saúde desse profissional na qualidade das suas práticas laborais. A atenção quanto às normas de biossegurança representa ao profissional, proteção de seu bem-estar, como também das instituições e/ou órgãos responsáveis ${ }^{26}$.

\section{Considerações Finais}

A partir do estudo, verificou que os ACS's se deparam com inúmeras dificuldades na realização das visitas domiciliárias, que tendem a prejudicar ou comprometer a efetividade do trabalho. $\mathrm{E}$, devido ao fato de atuarem em condições vulneráveis, com exposição aos fatores climáticos, difícil e longínquo acesso às residências, indiferença de parte da população, desvalorização da profissão e estruturas falhas acabam desmotivando, o que reforça suas fragilidades nas relações de trabalho.

Os resultados do estudo remetem à necessidade de maiores discussões com o objetivo de minimizar ou solucionar as barreiras persistentes no cotidiano assistencial desse grupo de profissionais. Além disso, há urgência de alocação de recursos materiais, maior atenção dos gestores, programas de capacitação continuada/permanente, sensibilização da população quanto à relevância do trabalho do ACS e ampliação da frequência de reuniões multidisciplinares como meio de articulação com os outros profissionais.

Esse direcionamento pode possibilitar a aproximação dos princípios do SUS e o melhor desenvolvimento das práticas do ACS. Práticas com enfoque para a participação comunitária, reflexão do processo saúde-doença e transformação da velha assistência baseada na doença e na cura. 
Ainda que, o estudo tenha revelado e reafirmado importantes particularidades do trabalho do ACS, houve limitações relacionadas a abrangência e a complementariedade de outras técnicas na coleta de dados, como por exemplo, entrevistas. Com isso, novos estudos devem ser realizados, valorizando os discursos diretos desses profissionais. Ademais, é fundamental o desenvolvimento de estudos complementares que possam entender as políticas de recrutamento, definição do currículo e perfil básico desse profissional para desempenho das práticas em saúde coletiva.

\section{Referências}

1. Costa SM, Araújo FF, Martins LV, Nobre LLR, Araújo FM, Rodrigues CAQ. Agente Comunitário de Saúde: elemento nuclear das ações em saúde. Ciênc saúde coletiva. 2013; 18(7):2147-56.

2. Gehn M, Gehlen MH, Ilha S, Nicola GDO, Zamberlan C, Backes DS. Percepção de usuários de saúde em relação às ações desenvolvidas pelos agentes comunitários de saúde. Disciplinarum Scientia. 2011; 12(1):27-37.

3. Santos MG, Ceretta LB, Schwalm MT, Dagostim VS, Soratto MT. Desafios enfrentados pelos Agentes Comunitários de Saúde na Estratégia Saúde da Família. Rev inova saúde. 2015;4(1):26-36.

4. Santana JCB, Fortes NM, Gonçalves CP, Moura IC, Porto PA. Visita domiciliar dos agentes comunitários de saúde no planejamento das ações das estratégias da saúde da família: avanços e desafios. Enferm rev. 2015; 18(2):18-28.

5. Souza LJR, Freitas MCS. O Agente Comunitário de Saúde: violência e sofrimento no trabalho a céu aberto. Rev baiana saúde pública. 2011; 35(1):96-109.

6. Baralhas M, Pereira MAO. Prática diária dos agentes comunitários de saúde: dificuldades e limitações da assistência. Rev bras enferm. 2013; 66(3):358-65.

7. Baratieri T, Marcon SS. Longitudinalidade no trabalho do enfermeiro: identificando dificuldades e perspectivas de transformação. Texto \& contexto enferm. 2012; 21(3):549-57.

8. Medeiros LNB, Guedes CDFS, Silva DR, Souza TKC, Costa AB, Neta BPAA. Condições laborais e o adoecimento dos agentes comunitários de saúde: revisão integrativa. Rev eletrônica estácio saúde.2015; 4(2):180-192.

9. Nascimento, A. R. A.; Menandro, P. R. M. Análise lexical e análise de conteúdo: Uma proposta de utilização conjugada. Estud pesqui psicol. 2006; 6(2):72-88.

10. Freitas H, Becker J, Martens CDP, Marcolin C. Sistemas de informação - temas de pesquisa acadêmica no brasil entre 1994 e 2013. Revista Eletrônica de Sistemas de Informação. 2014; 13(3):1-35.

11. Marzari CK, Junges JR, Selli L Agentes comunitários de saúde: perfil e formação Ciênc saúde coletiva. 2011; 16(supl.1):873-80.

12. Justo CMP, Gomes MHA, Silveira C. Limites e imposições dos instrumentos de controle do trabalho de agentes comunitários de saúde da estratégia de saúde da família. Saúde Soc. 2015; 24(2):594-606.

13. Freitas LM, Coriolano-Marinus MWL, Lima LS, Ruiz-Moreno L. Training of community health agents in the city of Altamira (Pará), Brazil. ABCS Health Sci. 2015; 40(3):171-77.

14. Santos AC. Curso técnico de agente comunitário de saúde: a percepção dos ACS [dissertação]. Rio de Janeiro: Fundação Oswaldo Cruz; 2015.

15. Baptistini RA, Figueiredo TAM. Agente comunitário de saúde: desafios do trabalho na zona rural. Ambiente \& Sociedade. 2014; 2:53-70.

16. Silva AOR, Neto FRGX, Teófilo TJS. Visita ao lar na estratégia saúde da família por agentes comunitários de saúde. Essentia. 2015; 16:140-155.

17. Braga GMAM, Mafra SCT, Silva EP, Gomes AP, Melo MSS. Percepção do trabalho do agente comunitário de saúde pelos usuários atendidos nas unidades básicas de saúde da família de Viçosa, MG: tarefas realizadas e normas prescritas. Oikos: Rev bras econ dom. 2016; 27(1):79-95.

18. Araújo MMT, Silva MJP. Estratégias de comunicação utilizadas por profissionais de saúde na atenção à pacientes sob cuidados paliativos. Rev Esc Enferm USP. 2012; 46(3):626-32.

19. Lanzoni GMM, Cechinel C, Meirelles BHS. Agente Comunitário de Saúde: estratégias e consequências da sua rede de relações e interações. Rev Rene. 2014; 15(1):123-31.

20. Anderle P, Souza BB, Julião GG, Millão LF, Santos CJ, Monteiro JAS. Perfil dos pacientes assistidos pela residência integrada em saúde: um olhar humanizado na assistência domiciliar. Aletheia. 2013; (41):164-73. 
21. Bellenzani R, Paro DM, Oliveira MC. Trabalho em saúde mental e estresse na equipe: questões para a Política Nacional de Humanização/SUS. Rev psicol saúde. 2016; 18(1):32-43.

22. Silva LMS, Fernandes MC, Mendes EP, Evangelista NC, Torres RAM. Trabalho interdisciplinar na estratégia de saúde da família: enfoque nas ações de cuidado e gerência. Rev enferm UERJ. 2012; 20(esp.2):784-88.

23. Moreira DA, Horta NC, Brito MJM, Pereira LA, Montenegro LC. Estratégias de organização e fortalecimento do trabalho da enfermagem na equipe de saúde da família. Rev enferm Cent-Oeste Min. 2016; 1(6):2106-18.

24. Frota OP, Ferreira AM, Loureiro MDR, Cheade MFM, Reis MG. O uso de equipamento de proteção individual por profissionais de enfermagem na aspiração endotraqueal. Rev Enferm UERJ. 2012; 20(esp.1):625-30.

25. Scheil-Adlung X. Global evidence on inequities in rural health protection: new data on rural deficits in health coverage for 174 countries. International Labour Office, Social Protection Department. - Geneva: ILO, 2015.

26. Brand CI, Fontana RT. Biossegurança na perspectiva da equipe de enfermagem de Unidades de Tratamento Intensivo. Rev bras enferm. 2014; 67(1):78-84.

\author{
Vagner Ferreira do Nascimento \\ Endereço para correspondência - Rua: Moreira Cabral, $n^{\circ} 475$, \\ Bairro: Campinas, CEP: 78600-000, Barra do Garças, MT, Brasil. \\ E-mail: vagnerschon@hotmail.com \\ Lattes: http://lattes.cnpq.br/4134268880865735 \\ Ana Cláudia Pereira Terças - enfanacnp@gmail.com \\ Thalise Yuri Hattori - thalisehattori@gmail.com \\ Bianca Carvalho da Graça - biaubatuba19@hotmail.com \\ Juliana Fernandes Cabral -ju_fcabral@hotmail.com \\ Josué Souza Gleriano - josue_gleriano@hotmail.com \\ Angélica Pereira Borges - angel.ufmt@gmail.com \\ Graziela Regina Machado de Souza Ribeiro - grazielamachado8@gmail.com \\ Enviado em 15 de julho de 2016. \\ Aceito em 15 de setembro de 2016.
}

